Plast poder: el ejercicio de poder estructural focalizado sobre los contenidos visuales (Guía de comunicadoras visuales en Costa Rica, año 2020)

Plast Power: the Exercise of Structural Power Focused on Visual Content (Guide of Visual Communicators in Costa Rica, year 2020) 


\title{
Plast poder: el ejercicio de poder estructural focalizado sobre los contenidos visuales (Guía de comunicadoras visuales en Costa Rica año 2020)
}

\author{
Plast Power: the Exercise of Structural Power Focused \\ on Visual Content (Guide of Visual Communicators \\ in Costa Rica, year 2020)
}

\author{
Albán Camacho-Lobo ${ }^{1}$ \\ Lanobienal \\ Cartago, Costa Rica
}

Recibido: 29 de octubre de 2019 Aprobado: 11 de mayo de 2020

\section{Resumen}

En el campo de la comunicación visual, se ejerce una forma de poder particular, que se ha conceptualizado como el plast poder: el ejercicio de poder estructural focalizado sobre los contenidos visuales, el cual tiende a normar los accesos a los capitales que desprende el campo. El plast poder actúa sobre los contenidos visuales; en particular sobre los elaborados por comunicadoras, por lo que se ofrece una guía que remite a las comunicadoras visuales sobre cuyos contenidos se ejerce con mayor fuerza este tipo de poder, en la Costa Rica actual.

Palabras clave: arte visual, teoría, feminismo, bordes, geografías.

\begin{abstract}
In the field of visual communication, a particular form of power is exercised, which has been conceptualized as the plast power: the exercise of structural power focused on the visual contents, which regulates the access to the capitals that the field gives off. The plast power acts on the visual contents, in particular on those prepared by communicators, so it offers a guide that refers to the visual communicators about our contents this type of power is exercised with greater force, in the actual Costa Rican.
\end{abstract}

Key words: visual art, theory, feminism, edges, geographies.

1 Investigador social y curador en Lanobienal. Bachiller en Sociología por la Universidad Nacional de Costa Rica. ORCID: 0000-0002-0389-6338._Correo electrónico: nefantus@hotmail.com 


\section{Introducción}

Este trabajo de investigación trata sobre las relaciones de poder en el campo de la comunicación visual y se aporta, también, una guía de comunicadoras visuales de Costa Rica. Esta propuesta es producto del esfuerzo que se realiza desde la Coordinación de Investigación Social de Lanobienal, un proyecto de gestión cultural e investigación costarricense que promueve la divulgación de contenidos visuales inclusivos. Desde este espacio, se ha desarrollado un proceso de investigación que, en un inicio, partió de la pregunta generadora: cuando la obra de una comunicadora o un comunicador visual es rechazada de una bienal de arte, ¿se ejerce poder sobre el cuerpo del agente que comunica o sobre el contenido visual que elabora? De la respuesta a esta interrogante, surge la consideración de que, a pesar de que hay un alcance sobre el cuerpo del agente que comunica visualmente al facultar -desde un sistema de opresión y privilegios-accesos a los capitales presentes en el campo, es más evidente que se produce una forma particular de poder que se ejerce sobre el contenido visual.

Es en el contenido visual donde se genera la desigualdad en la posición que ocupan las y los agentes en el campo con respecto al acceso a los capitales desprendidos. Al pensar en este particular, desde Lanobienal se diseñó y presentó el conversatorio titulado "Presencia y ausencia de espacios para la divulgación de la comunicación visual", el cual fue realizado en la Escuela Casa del Artista del Ministerio de Cultura y Juventud, en setiembre del año 2017, con la moderación de quien suscribe y cuyo propósito fue contribuir a dilucidar cómo se comporta el poder en el campo de la comunicación visual. Las y los panelistas, L. Sancho, K. Pérez Baes, O. Morales y Y. de La Paz, concluyeron que, aunque existen espacios para divulgar los contenidos visuales, las y los artistas no están teniendo acceso a estos, pues existen diversas fuerzas en el campo que ejercen poder sobre las elaboraciones plástico-visuales.

A partir de lo anterior, se consideró, de modo general, que en la historia de Costa Rica nunca habían existido tantos espacios y medios para divulgar los contenidos visuales como en la actualidad. Sin embargo, en ellos se ejerce poder sobre las elaboraciones de las y los comunicadores, de forma tal que el aprovechamiento y la distribución de los recursos desprendidos en el campo se dan de manera desigual entre las y los agentes que comunican visualmente. A la vez, el proceso de investigación llevado por el suscrito desde Lanobienal se hizo acompañar del apoyo de las profesoras del grado de licenciatura de la Escuela de Sociología de la Universidad Nacional (S. Rojas, L. Gonzales, L. Brenes, A. Salazar, Y. 
Plast poder: El ejercicio de poder estructural focalizado sobre los contenidos

Artículo visuales (Guía de comunicadoras visuales en Costa Rica año 2020)

Vargas y $\mathrm{V}$. Cruz), quienes facilitaron los contenidos teóricos y metodológicos oportunos para el desarrollo de este artículo de investigación, durante los años 2017-2018-2019.

Para la elaboración de la guía de comunicadoras visuales se aprovechó el alcance de las plataformas de gestión cultural Lanobienal y Galería Ave Fénix del Taller del Artista, en las cuales el autor de este artículo ha participado como curador. De ese modo, entre el año 2016 y el 2020 se realizó una serie de muestras de arte de las que surge, en su mayoría, la lista de comunicadoras visuales que aquí se ofrece. Dichas participaciones curatoriales se detallan a continuación: Lanobienal 1era edición (2016), llevada a cabo en la galería Croma; Infestación (2017), realizada en galería Ave Fénix; Geo Feminista: indicadores plásticos de opresión, desigualdad y privilegio (2018), diseñada desde Lanobienal, presentada en La Casa de Cultura Popular José Figueres Ferrer; Relaciones de poder (2018), expuesta en Salón de Proyectos de la galería Ave Fénix; Autonomía liquida (2019), la cual formó parte del sub proyecto curatorial de Lanobienal Ilamado La Muestra Inclusiva, lanzada en la galería El Triángulo. La Muestra de videoarte LGTBI, adscrita al Festival de Cine Diverso NOSFF, (2019) también acontecida en la galería Ave Fénix. Se cerró con la 3era edición de Lanobienal (2020), sobre el Arte de la Tierra (Land Art), realizada en Finca Donde Miguel, Taller del Artista y Centro Cultural San José.

\section{Plast poder, exclusión social y comunicación visual}

En Costa Rica, el desarrollo de la comunicación visual en las décadas de la globalización (de 1980 en delante) ha venido acompañado de una forma de ejercicio de poder estructural que tiende a redefinir las nociones de validez acerca de lo que se puede llegar a tener como producto cultural desde este tipo de comunicación y lo que no. Tal proceso es paralelo a una reestructuración sistémica que se desprende de los eventuales convencionalismos éticos propios del periodo del Estado de bienestar y que se circunscriben en la lógica neoliberal del predominio medios-fines y el auge de las relaciones humanas posmodernas organizadas a través del mercado y de las emergentes tecnologías de la comunicación. Al respecto, Vargas (2001) indica que:

En las postrimerías del siglo XX toma fuerza un nuevo orden mundial sustentado en la reorganización de las viejas estructuras capitalistas, gracias a la coincidencia de ... la crisis y caída del socialismo real, el vertiginoso desarrollo de nuevas tecnologías de la información y la comunicación y el fortalecimiento de las ideas neoliberales (p. 35). 
En el campo de la comunicación visual en Costa Rica, el acceso a los capitales de diversa índole ha tendido a generarse desde posicionamientos diferenciados entre los agentes que se vinculan a este área. De esta situación, se desprende que grupos de artistas visuales, cuyos contenidos no comunican en forma positiva los criterios que requiere el sistema patriarcal-capitalista-occidental para su propia validación, tienden a sufrir de una forma de vulnerabilidad por exclusión.

Al respecto de cómo se configuran las relaciones de poder desde los accesos a los capitales presentes en el campo, Bourdieu (1976) señala que "el sistema social es el resultado de las relaciones de fuerzas entre clases o grupos sociales ... fracciones de clases sociales se configuran por la posesión de un determinado capital económico, social y cultural” (p. 59). También, se evidencia el ejercicio de una forma de poder que trasciende al cuerpo del agente que comunica visualmente, pues esta actúa sobre la obra plástica derivada del desempeño del artista, materializada desde el objeto, la imagen y el concepto. Este tipo de poder particular determina cuáles productos visuales son válidos para consumos masivos y cuáles no, desde el acceso a la divulgación de estos y a los capitales diversos. En este artículo, a tal categoría se le reconocerá con el nombre de plast poder.

El plast poder corresponde al ejercicio de poder estructural focalizado sobre el contenido visual desde sus procesos de validación. Este reviste los criterios de validez de los grupos dominantes en un entorno social específico, al generar formas de violencia visual y semiótica sobre los grupos dominados en el proceso. Su fin sistémico reside en el acceso público, o no, a los contenidos y conocimientos derivados de las diferentes prácticas de la comunicación visual.

Respecto de cómo las fuerzas que actúan en el campo generan procesos de marginación de grupos ubicados desigualmente, el trabajo investigativo de Cubillos (2017) orienta esta reflexión sobre la exclusión al indicar que esta "sugeriría un proceso dinámico, multidimensional y relacional, en el que coinciden ... una serie de privaciones que empuja a los individuos al margen de la sociedad, lo que amenaza su vínculo con la comunidad" (p. 356). Tal marginalidad a la que se ven expuestos las y los comunicadores visuales que tienen ubicaciones menos ventajosas en el campo remite al ejercicio de poder dominante y a los discursos en los que se sustentan, dado que los contenidos privilegiados facilitan accesos a los capitales, de forma más expedita, para sus creadoras y creadores. 
Plast poder: El ejercicio de poder estructural focalizado sobre los contenidos

Artículo visuales (Guía de comunicadoras visuales en Costa Rica año 2020)

En el entorno de la cultura, entendida esta como aquella nomenclatura de discursos, códigos, normas de asimilación subjetiva, que tienden a estructurar un sistema social por su competencia generalizada y que desprenden conductas con validez colectiva, se inscribe la práctica de la comunicación visual. Desde tal forma de comunicación, un grupo social expresa con códigos visuales específicos los componentes del tipo de poder en el que se fundamenta tal orden sistémico. Pareciese ser que "las cosas representadas en imágenes cuentan y pesan más que las cosas dichas con palabras" (Sartori, 1998, p. 26). En virtud de lo anterior, se tienden a generar procesos de exclusión de aquellos grupos cuya producción visual, contenidos conceptuales y semióticos, que de esta se desprenden, escapan de los lineamientos de función requeridos por los grupos de poder hegemónico en un tiempo y espacios específicos. Es por lo que se señala lo que indica Ariño (2002), citado por Giner (2003), quien dice que: "este carácter genérico, constitutivo, de la cultura no agota la totalidad de sus dimensiones: aquella no sólo opera como un imperativo funcional para la integración social, sino que también puede intervenir como un factor de exclusión de determinados grupos" (p. 306). Estos grupos sobre los que se ejerce opresión en forma de exclusión son los que sufren de mayor grado de vulnerabilidad.

En este orden, aquellos grupos de artistas cuyos contenidos discursivos y ejecución performática tienden a mostrar rendimientos contrarios a las necesidades de función sistémica, desde la validación que la y el comunicador visual generan con su trabajo plástico y suelen padecer de exclusión de las dinámicas productivas y de generación de capitales asociados a estas. Es allí, en tal forma de ejercicio de poder estructural sobre el agente que elabora desde la comunicación visual, que se advierte una tendencia hacia tal contenido de exclusión. Según la guía brindada por Cubillos (2017), se señala que:

La exclusión adquiere diversas intensidades, afectando de manera cambiante a personas y colectivos, a partir de las modificaciones que estos puedan sufrir en los aspectos más o menos vulnerables a las dinámicas de marginación (p.e. enfermedades, desempleo, cambios de residencia). Las situaciones de exclusión pasarían por un itinerario largo y complejo de fronteras móviles y fluidas, entre zonas de integración hacia zonas reconocidas como de precariedad, vulnerabilidad y marginación hasta la exclusión misma (p. 357).

La inclusión social tiende a omitir los criterios de legitimación de los grupos dominantes sobre aquellos a los que compete la desigualdad presente en el proceso de exclusión social. Las interseccionalidades de las personas en condición de vulnerabilidad 
sistémica desprenden relaciones de dominación desde las validaciones hegemónicas patriarcales basadas en el género, la clase social y la etnia. Las dinámicas de privilegios y privaciones que delimitan el mundo de la experiencia desde el mercado como eje referencial tienden a confluir con los criterios de legitimación de los grupos que detentan el poder y cómo este tipo de ejercicio de poder delimita un ejercicio de comunicación visual que reviste los criterios de dominación imperantes propios del sistema patriarcal y capitalista. Estos renovaron su estructura con la emergencia de las relaciones comerciales de mayor rendimiento de la globalización y con la emergencia de nuevas formas de intercambio de información en las postrimerías de la Guerra Fría.

\section{Transformación estructural, modelo neoliberal y comunicación visual}

La introducción de los Programas de Ajuste Estructural, conocidos como PAE, en Costa Rica a partir de 1984 y la emergencia de un mercado global modificaron las estructuras sistémicas al orientar la función hacia la integración con una economía mundializada a través de los Tratados de Libre Comercio y de la reconversión de las estructuras productivas de capitales, lo que reposiciona, desde los intereses neoliberales, el acceso a los capitales generados y a su generación. Esto incide en el campo de la comunicación visual, pues esta transformación paulatina de las estructuras productivas en el país reviste una forma de ejercicio de poder que favorece los conocimientos técnico-prácticos vinculados a las ingenierías, donde se sacrifican las aportaciones para el desarrollo o fortalecimiento de programas con contenidos sociales y culturales en los subsistemas donde se padece del proceso globalizador.

De acuerdo con Corrales (1994), este tipo de políticas implementan transformaciones radicales para el entorno del Estado de bienestar social demócrata, puesto que se promueve la reducción del sector público, liberalización de precios y libre contratación, así como la apertura del mercado interno al mercado global. Además, utilizan los PAE para realizar la transformación de las estructuras y, a la vez, sus criterios de validez propios, en los cuales resultan de interés el uso de medios visuales para comunicar. Cabe señalar que, tal y como lo indican diversos autores y autoras, se han dado en estudiar los alcances técnicos de las políticas neoliberales. Sassen (2003) indica que "el propósito de estos programas era promocionar la competitividad de las economías estatales, lo que comúnmente significa agudas reducciones a los programas sociales (culturales)" (p. 32). 
Plast poder: El ejercicio de poder estructural focalizado sobre los contenidos

Artículo visuales (Guía de comunicadoras visuales en Costa Rica año 2020)

Las transformaciones en el sistema social en Costa Rica, a partir de la década de 1980, generaron modificaciones en la forma en que sus agentes se comunican visualmente, puesto que las reglamentaciones estructurales se amoldaron a los nuevos requerimientos de generación de conocimiento visual. La estructura delimita los procedimientos y contenidos discursivos en función de las necesidades propias de los grupos de poder dominantes emergentes con la introducción del modelo neoliberal, el cual, en su condición extractivista, suele ser más agresivo con los grupos en condición de vulnerabilidad de algún tipo, puesto que, por su origen masculinizado, favorece el criterio técnico propio de la lógica medios-fines que tiende a desarrollarse "a partir de un análisis formal y riguroso de 'calculabilidad', a partir de las relaciones de intercambio ... y de su expresión en dinero" (Hinkelammert \& Mora, 2001, p. 89). Por ende, la estructura tiende a optimizar los procedimientos sistémicos de acuerdo con la implementación de un modelo emergente.

Los requerimientos de función que emergen al implementar políticas propias del modelo neoliberal responden a un grupo de transformaciones que modifican los lineamientos que contestan a la validación de los discursos de los grupos que detentan el poder. En el caso de los grupos que emergen con el modelo neoliberal, estos privilegian los discursos masculinizados de tipo tecnocrático, en los cuales las ingenierías detentan una ubicación central; idea predominante en el acercamiento a los procesos de elaboración de cultura, al delimitarse una normativa emergente al mundo de la experiencia de las y los agentes que actúan en el campo. Esto se traduce en la implementación de transformaciones evidentes; tanto en el tratamiento objetivo de materiales y técnicas para comunicar visualmente, como del tratamiento subjetivo de signos y significantes comunicados y su afinidad ética, y en tanto a la posición que el campo de la comunicación visual ocupa con la emergencia del modelo neoliberal. Dentro del modelo neoliberal, la comunicación visual tendrá la función de transmitir los nuevos códigos visuales propios de la globalización del mercado patriarcal y capitalista.

La comunicación visual es integrada como elemento funcional del modelo neoliberal que, al comunicarlo, sustenta el ejercicio de poder de los grupos que salieron ventajosos con la implementación de las políticas neoliberales. Introduce modificaciones afines a sus propios requerimientos en los usos propios o procedimientos de validación dentro del campo de la comunicación visual. Se validan sus propios contenidos de función en un proceso que se respalda en el privilegio de la divulgación del conocimiento visual y en el goce efectivo de los recursos disponibles en el campo por parte de los agentes que reproducen los contenidos de la cultura dominante: patriarcal, neoliberal y posmoderna.

ESCENA. Revista de las artes, 2021, Vol. 81, Núm. 1 (julio-diciembre), pp. 85-112 
Reuber (1995), en pleno auge neoliberal en Costa Rica de la década de 1990, señalaba que, con la implementación de las políticas neoliberales, el "resultado es una paulatina transformación de la estructura económica nacional a imagen y semejanza de la estructura económica mundial, mediada por el aplacamiento casuístico de las reacciones que provoca entre sectores sociales" (p. 25). Con la sustitución del modelo de desarrollo nacional de corte social demócrata por uno de tipo neoliberal y globalizador, se desplazó al Estado en su papel de garante y ejecutor de una relativa apropiada distribución de la riqueza. Se implementó, en cambio, un modelo de tipo extractivista, que agudiza las desigualdades sociales por las capacidades de acceso a los capitales y los posicionamientos de los agentes en el campo.

Lo anterior faculta un reposicionamiento de los grupos que actúan en el campo de fuerzas dado en las geografías de la comunicación visual, donde la reacción que provoca el ajuste estructural transforma, paulatinamente, los criterios que validan tanto los contenidos, como las técnicas pertinentes para comunicar visualmente. A la vez, promueve una reubicación en el campo de los grupos que detentaban posiciones privilegiadas en el acceso a los capitales diversos presentes en este, junto con los que se reposicionan diferenciadamente y otros que emergen con la apertura a la globalización y del retroceso tradicionalista. Para cerrar este apartado sobre políticas neoliberales y comunicación visual, se remite lo indicado por el investigador Bustos (1995), quien apunta que el neoliberalismo:

Es un proceso de desnacionalización de las economías mediante el establecimiento de redes transnacionales de producción, comercio y finanzas ... actualmente existe una economía global cada vez más integrada que las necesidades del capitalismo imponen a todos los gobiernos una disciplina económica neoliberal (p. 5).

Las políticas económicas neoliberales impactaron en el campo de la comunicación visual de forma diferenciada a las y los actores. Hubo grupos que resultaron ventajosos; otros, como en el caso de los artistas plásticos tradicionales, fueron perdedores. Ejemplo de este señalamiento es la experiencia acaecida con la Bienal de Escultura del año 1999.

\section{La IV Bienal de Escultura, posmodernidad y plast poder}

Los contenidos visuales y las prácticas privilegiadas, previo al periodo globalizador, respondían a los intereses de los grupos de poder económicos y políticos vinculados al ejercicio partidario y a la centralidad del Estado. Lo que acontece con la emergencia de la globalización introducida con el modelo neoliberal es que el tipo de contenidos visuales, su 
Plast poder: El ejercicio de poder estructural focalizado sobre los contenidos

Artículo visuales (Guía de comunicadoras visuales en Costa Rica año 2020)

tratamiento estético y ético, y las áreas de la comunicación visual favorecidas por el interés estructural varían sus centros y desplazan hacia los márgenes los contenidos en una relación de cálculo medios-fines. Esto generó una tensión estructural en el campo de la comunicación visual, que era inversamente proporcional al grado de emergencia de nuevas técnicas, medios, contenidos, áreas de acción social y actores en el campo.

En el ejemplar del diario costarricense La Nación del viernes 5 de noviembre de 1999, la periodista Camila Schumacher Ladanyi publicó un artículo titulado Es... ¿culturas?: La IV Bienal de Escultura de la Cervecería Costa Rica desata críticas, en el cual se dirime la protesta de las y los escultores consolidados (M. Vargas, C. Badilla, A. Jiménez, L. Astorga, D. Ramos) que ven a la IV Bienal de Escultura como una amenaza que descentra el uso de las técnicas, los medios y contenidos tradicionales, y legitima, al traer al centro, las prácticas de artistas emergentes (P. Arrieta, P. Monge, A. Carranza, G. Tovar, A. Camacho), cuya elaboración se aproxima con mayor afinidad a la transformación que se acentuaba desde una década atrás en el campo del arte visual con la emergencia de la globalización. La molestia de este grupo de escultores lo plasma Schumacher Ladanyi, al entrevistar a Manuel Vargas, quien indica en la entrevista: "hay piezas entre las seleccionadas por el jurado que ... no por ser objetos en tres dimensiones pueden considerarse esculturas. Las nuevas propuestas ... sólo [sic] causan confusión ... el jurado no seleccionó un número significativo de obras talladas, modeladas o fundidas" (Schumacher, 1999, p. 6).

En este caso, en el campo que despliega la práctica escultórica, por ejemplo, se observa cómo la tensión que es provocada por las transformaciones estructurales en el eje del conocimiento, derivado de esta práctica en el campo de la comunicación visual, genera una fricción por el reposicionamiento de discursos y ubicaciones a los accesos de los capitales diversos presentes en el campo, por parte de los agentes que en este actúan. "En toda sociedad se suscita una lucha por su propia simbolización. Es parte de la pugna ideológica: de lo emergente contra lo dominante" (Acha, 1996, p. 25). Se observa, así, la resistencia de los grupos que detentaban ubicaciones privilegiadas en el campo, como reacción a la tensión estructural a la que estaban expuestas sus elaboraciones plástico-visuales. Las réplicas de la jurado del evento vinieron de la curadora Vivian Loría, al referirse al cambio que se promovía en el campo con el proceso globalizador:

Hay quienes no ... investigan, no miran, no se preguntan qué está pasando y por eso se van quedando por fuera ... los trabajos seleccionados, que en su mayoría son instalaciones, trabajan el objeto y el ambiente impecablemente, son vivos, sugestivos y consecuentes con lo que se proponen (Schumacher, 1999, p. 6).

ESCENA. Revista de las artes, 2021, Vol. 81, Núm. 1 (julio-diciembre), pp. 85-112 
Esta situación, que trascendió a la prensa local, se hizo acompañar de una carta de protesta firmada por el grupo de escultores tradicionalistas ante las autoridades de La Bienal de Escultura, lo que desembocó en el cierre del evento a partir del desmontaje de la muestra de las salas de la Galería Nacional en el año 2000; como efecto de la acción social surgida de la tensión estructural inducida con la implementación del modelo neoliberal, generó un agudizamiento de la lucha de fuerzas que se da en el campo. El despliegue técnico y conceptual partían de un centro de racionalidad tradicional; se pasó a una reglamentación del campo que favorece el tratamiento técnico de origen industrial y superpone el talento conceptual al talento manual, como expresión del fin de los relatos modernos de transmisión institucional, según la generación del conocimiento y sus medios de legitimación en el campo de la comunicación visual. Se ubicó el uso de los recursos en función del mercado global, al descentrar la atención del mercado local.

Se instaura, a partir de este evento, en el medio del arte visual costarricense, la posmodernidad como base teórica procedimental de las elaboraciones plástico-visuales en este subsistema que se presenta a modo de campo de acción, en el cual las nomenclaturas se transformaron con afinidad a los requerimientos de función introducidas con la globalización y el modelo neoliberal. Se instauró la idea de que se ha llegado al fin de los meta-relatos en el campo del arte en Costa Rica, lo que supone la pérdida de centralidad de los espacios de validación tradicional y sus discursos asociados. Esto generó una combinación y asimilación entre el proceso globalizador y la transformación de los conceptos, las técnicas y los medios de legitimación en el campo de la comunicación visual. Para Castells (2006), la posmodernidad es el relato del fin de las concepciones de tipo moderna, solidaria, estatista, racional, burócrata y análoga.

La cultura y la teoría posmoderna se recrean en celebrar el fin de la historia, y en cierta medida el fin de la racionalidad, rindiendo nuestra capacidad de comprender y hallar sentido ... la aceptación de la plena individualidad de la conducta y la impotencia de la sociedad sobre su destino (p. 30).

El final de los relatos modernos de la centralidad del Estado, la burocracia y la asociación popular supone traer al centro a grupos de poder emergentes que vienen a validar sus propios contenidos, los cuales representan a un grupo más agresivo de capital que se ha desprendido de las ataduras del poder estatista y celebra la opresión sobre las prácticas de los grupos sociales que han salido perdedores en el proceso globalizador, los que centralizan el relato de dominación total en un acto místico que evoca sus propios misterios 
Plast poder: El ejercicio de poder estructural focalizado sobre los contenidos

Artículo visuales (Guía de comunicadoras visuales en Costa Rica año 2020)

al ocaso de la civilización. La discusión alrededor del concepto de "la mística del ocaso" que Nietzsche propone como relato de la dominación burguesa, según el trabajo que desarrolla Hinkelammert (1996), se maximiza al promoverse una actuación humana en un periodo de desencanto con el proyecto cultural dominante, basada en el cálculo de interés propio como eje estructurante de las relaciones humanas.

La lógica medios-fines plantea la superación de las formas de relación recíproca alrededor de los valores de uso. Con la superación de los relatos universales, "el horizonte utópico", propuesto por el reconocido investigador, promueve un mayor rendimiento en la perfomatividad de los procedimientos en función del modelo neoliberal y de su sistema de mercado como relato "final" de dominación. "Nietzsche ... describe un universo de dominación idealizado. Es el mundo de una nueva aristocracia que lucha entre sí por la dominación" (Hinkelammert, 1996, p. 144). La comunicación visual en este entorno de incertidumbre con la introducción fragmentada de discursos, prácticas y geografías emergentes se torna, por un a lado, más afín al sistema de mercado global y, por otro, menos afín al tratamiento tradicional y formal de los contenidos y las técnicas de elaboración.

El sistema de comunicación visual acciona según los lineamientos rectores del mercado global, que optimiza sus procedimientos con la función medios-fines que tiende a generar exclusión, dado que en el proceso quedan artistas en condición de desventaja, lo que incide negativamente en el desarrollo de tendencias visuales propias de una sociedad. Se derivan, así, procesos de violencia semiótica sobre los grupos humanos en condición de dominados en vulnerabilidad. Entre estos, los contenidos y las experiencias tenidas por mujeres en el campo de la comunicación visual se vuelven de interés por la condición de opresión y de marginalidad históricamente dada.

\section{Comunicación visual elaborada por mujeres, arte feminista y bordes}

El campo de la comunicación visual tiende a estar, al igual que el sistema, altamente masculinizado. Además, se ha generado, a lo largo del tiempo, un cuerpo de apoyo que se ha plasmado a modo de políticas públicas y de gestiones privadas, comunales o filiales, en función de las necesidades de los comunicadores visuales hombres, por lo que la participación de las mujeres en el campo se realiza desde un posicionamiento desigual, lo mismo que el de otros grupos en condición de vulnerabilidad sistémica. En este sentido, la investigadora Álvarez (2006) apunta que:

ESCENA. Revista de las artes, 2021, Vol. 81, Núm. 1 (julio-diciembre), pp. 85-112 
La sociedad moderna se encuentra regida por una lógica masculina en la cual se hace evidente la ausencia de ... las experiencias de las mujeres y los significados sociales que ellas les otorgan ... Lo anterior no es en tanto un desconocimiento inocente ya que lo denominado como realidad social ha estado y permanece valorado por una normativa que separa un mundo aparte para los hombres y otro para mujeres, disponiendo así, jerarquía y discriminatoriamente la exclusión de las mujeres de la sociedad, las artes y la cultura (p. 6).

En el ejercicio de plast poder se norma el acceso a los capitales diversos presentes en el campo desde la divulgación de los contenidos visuales, en particular, los elaborados por grupos sociales en condición de vulnerabilidad sistémica. Los realizados por mujeres revisten un tipo particular de ejercicio del plast poder, puesto que este adquiere formas variadas de actuar. A través del acceso a las geografías de validación de contenidos visuales, se puede eventualmente presentar una condición de vulnerabilidad, incluso, de tipo sexual, por el predominio de hombres en puestos de mando en el campo de la comunicación visual. La norma que se ejerce sobre el contenido visual puede llegar a vulnerar el mismo cuerpo de quien actúa como comunicadora visual; según la investigadora social Mandel (2006), lo anterior sucede, si se parte de que el "cuerpo femenino es considerado por la sociedad patriarcal como un espacio simbólico relegado y dependiente de otras voluntades" (p. 12). Desde el ejercicio particular del plast poder, a la vez, se tenderá a normar los contenidos propios relativos al feminismo como género, etnia y clase social, con mayor arraigo. En estas categorías descansa la estructuración del sistema de opresión y los privilegios que facultan el proceso de dominación. En este sentido, la socióloga Charles (2017) apunta que:

El argumento de neutralidad del arte respecto al género se resquebraja tan pronto se entiende que el arte ocurre dentro de una estructura social, cuyos elementos integrales son mediados por instituciones específicas que no son ajenas al debe ser de las mujeres y los hombres (p. 18).

Los procesos de exclusión presentes en la comunicación visual, que revisten la forma de un ejercicio particular de poder estructural, el plast poder, impactan con mayor fuerza las elaboraciones visuales de las comunicadoras, a la vez que las vulnerabiliza de otras formas. Por ende, se consideran las categorías propias del feminismo de género, raza y clase social, a la hora de valorar las propuestas realizadas por las comunicadoras visuales, al buscar su acercamiento con un tipo de "arte feminista" que tienda a revertir, desde la obra, el impacto del plast poder en los procesos de muestra y validación de las elaboraciones de 
Plast poder: El ejercicio de poder estructural focalizado sobre los contenidos

Artículo visuales (Guía de comunicadoras visuales en Costa Rica año 2020)

comunicación visual realizadas por mujeres. A la vez, la investigadora Sosa (2010) señala, en su trabajo sobre arte feminista, que:

El término "arte feminista" no implica automáticamente un tratamiento formal o temático, y sí implica un aspecto distinto a la concepción masculina del arte, el interés del artista no es tanto la obra en sí, sino que esta es el resultado de una vivencia personal (p. 188).

Al delimitar el producto de la elaboración visual más allá de la elaboración como objeto de consumo o como medio de simbolización social, se pasa por el tramado de la experiencia y la subjetividad femenina. "El arte feminista afirmará que el arte puede ser social y estéticamente efectivo" (Sosa, 2010, p. 188), por lo que el alcance de la penetración del arte como pieza de consumo, de representación o transformación social se tamiza de la visión femenina y de los contenidos propios del feminismo, al apuntar el transformar las relaciones de poder desigual. Por lo que, como se mencionó, las geografías que actúan en el campo de la comunicación visual debiesen facultar el empoderamiento femenino y la minimización de las formas de exclusión y violencia estructural ejercida sobre estas y sus elaboraciones visuales. Vuelve a señalar Sosa (2010): "en este sentido, el arte feminista remplazo al monologo moderno (y) ... va a ser deliberadamente incisivo en el contexto social y público, caracterizado por un elemento de otredad ... más allá del producto y del proceso artístico" (p. 188). La promoción del posicionamiento diferenciado de los discursos feministas en el campo de la comunicación visual reviste la resignificación de los productos visuales, los procesos detrás de estos y los contenidos manifiestos.

Los feminismos se sitúan al margen del campo androcéntrico. Los bordes remiten a las desigualdades presentes en un determinado campo producto del proceso de opresión y privilegios. Como tal, el borde remite a la marginalidad que se genera, producto de la radicalización de los enfrentamientos que se da en el campo por posicionarse de forma privilegiada en el acceso a los capitales presentes en el campo, durante procesos de reestructuración sistémica y en los centros remergentes manifiestos. Bourdieu (1990), citado por Charles (2017), señala que: "dado que en las sociedades "modernas" la vida se reproduce en campos (económico, político, científico, artístico) el análisis ... indagará cómo luchan por la apropiación del capital que cada campo genera los grupos que intervienen en él” (p. 28). Es en el posicionamiento diferenciado entre los agentes que actúan en el campo donde por procedimiento se ubican centros y bordes.

ESCENA. Revista de las artes, 2021, Vol. 81, Núm. 1 (julio-diciembre), pp. 85-112 
El proceso de construcción de la obra, sus significados latentes y sus relaciones ocultas se perfilan en cómo se configura el lenguaje plástico, en una tarea de deconstrucción del discurso dominante siempre presente en la elaboración humana. Los signos visuales dominantes en un entorno reiteran el tipo de poder dominante ejercido y cómo este atraviesa transversalmente la construcción social en la que se validan, preferentemente, los criterios que legitiman a los grupos que detentan el poder, desde su posicionamiento privilegiado en el campo. Estos grupos han construido sus propios discursos, medios, prácticas y geografías de validación, afines a sus propios intereses, al facultar los contenidos visuales dominantes.

Traer a análisis las relaciones marginales acontecidas en los bordes rompe con la forma logocéntrica de elaboración propia de occidente, que ha perfilado relaciones sociales; desde los intereses de los grupos que detentan el poder hasta el antagonismo del código binario que opone relaciones construidas desde la negación de lo otro: "bueno-malo", "blanco-no blanco", "rico-pobre", "hombre-mujer", "cielo-infierno". Los bordes, para Mandel (2006), se catalogan según su origen en dos tipos: espaciales y discursivos. Los espaciales refieren a los elementos que constituyen la obra y el límite que modelan al acatar o romper los espacios preestablecidos, mientras incorporan elementos complementarios al comunicar la idea. Por otro lado, el borde discursivo o intertextual apunta, por un lado, a develar las relaciones de la obra con otras y con el trabajo de otras autoras y, por otro lado, indaga sobre la acción del texto sobre la imagen. En este sentido, la socióloga Mandel (2006) establece, en su trabajo sobre el cuerpo como texto de elaboración artística, que:

El trabajo en los bordes es un trabajo deconstructivo que nos conduce hacia el camino ... sobre los modos en que se configura el lenguaje artístico. Las diversas instancias de los bordes espaciales y temporales ... están centrados en ... la reflexión acerca de los modos en que se construyen los signos visuales (p. 27).

La reflexión sobre el borde, espacial o discursivo, que conforma la obra devela el tipo de poder presente en ella y cómo este ejercicio de poder atraviesa a la obra y a la comunicadora visual en el proceso. Traer el borde al centro es desmasculinizar los procesos de creación y significación de la obra. Los contenidos céntricos privilegian los intereses del hombre, blanco, rico y occidental como figura céntrica y culturalmente dominante. La construcción de la obra no logocéntrica, no masculinizada, pasa por la disposición de multiplicidad de centros. La obra así concebida ubica su atención en la vivencia y el aprendizaje de la autora, como experiencia subjetiva; descentra la atención del arte objeto de consumo como experiencia objetiva. Esto implica la deconstrucción de la comunicación visual y sus productos 
Plast poder: El ejercicio de poder estructural focalizado sobre los contenidos

Artículo visuales (Guía de comunicadoras visuales en Costa Rica año 2020)

inherentes. Continua Mandel (2006) en esta línea: "aspectos considerados marginales, al ser centralizados, abandonan su condición de ... paralelos al hecho, para convertirse en 'ergón' (obra), constituyendo una de las principales características del arte contemporáneo ... develar los modos en que las obras fueron pensadas y constituidas" (p. 27). La comunicación visual en un entorno de predominio teórico y empírico del feminismo variaría los lineamientos del uso y alcance del plast poder hasta romper con los usos referenciales de tradición occidental y patriarcal al promover su desuso ante la imposibilidad de encontrar centros referenciales a los que responda el marco referencial de análisis teórico.

\section{Conclusiones}

La construcción de sistemas teóricos de interpretación de la realidad que promuevan valoraciones objetivas cimentadas en un conjunto de ideas que, al articularse entre sí, facultan la aprehensión de datos oportunos que develen el proceso de función del sistema es prioridad para revertir el poder impositivo de las estructuras de dominación sobre las personas y, en este caso, sobre los contenidos visuales producidos por ellas. El plast poder es presentando como marco teórico referencial para la interpretación de los procesos reales desde el campo de la comunicación visual, como teoría del arte que describe la afinidad de la obra en función del sistema de dominación. El considerar el contenido visual en función de las condiciones estructurales en las que se produce, dónde y por quién se facilita, a través de los procesos de obtención de datos descripciones asertivas de los procesos de comunicación visual, los vínculos del contenido con el poder dominante, la ubicación del agente que comunica en el campo y devela los discursos dominantes que imperan en un tiempo y espacio dados. Al respecto de la construcción teórica, Acha (1979), citado por Olivar (2015), indica que "entendemos la teoría como un cuerpo de ideas, conocimientos e imágenes, representaciones que puede ser empleado sistematizada o ingenuamente para penetrar la realidad y conocer sus posibilidades de cambio" (p. 324). La producción de una teoría en la línea del plast poder es oportuna y fundamental para encontrar, develar y explicar momentos diferenciados entre un punto y otro, en virtud de las relaciones de poder dominantes en entornos sociales específicos.

Los aportes del plast poder como marco teórico referencial para los procesos sociales inherentes a la comunicación visual se encuentran en su capacidad descriptiva como cuerpo de conocimiento técnico sobre la forma y el tipo de poder estructural que emerge en la región de Centroamérica y, particularmente, en Costa Rica, con la implementación de 
las políticas neoliberales y la renovación de las estructuraciones de poder patriarcal según sus signos y contenidos visualmente comunicados.

A la vez, la teoría del plast poder promueve procesos de obtención de datos acerca de la producción de contenidos visuales desde las categorías propias del feminismo de género, raza y clase social al ser contempladas desde la herramientas de la intersección, pues, por el tipo de ubicación particular del agente en el campo, devela la base del conocimiento visualmente propuesto. Para el caso de la investigación realizada sobre los procesos de poder propios del campo de la comunicación visual, facilita la interpretación previa al proceso descriptivo del sistema en particular. El reto de generar marcos compresivos sobre las realidades que se aparten de las pretensiones neocoloniales asociadas a la producción de contenidos visuales y de las propuestas teóricas en el escenario de la globalización ha sido angular en la elaboración de la categoría teórica del plast poder, como herramienta que facilita los procesos interpretativos requeridos para describir, acertadamente, los lineamientos de dominación cultural imperantes.

En ese sentido, continua Acha (1979), citado por Olivar (2015), cuando dice: "nos falta apoderarnos de los respectivos sistemas de producción de teorías artísticas ... necesitamos iniciar la apropiación estética de la teoría del arte ... carecemos de producción de teorías" (p. 306). El plast poder ofrece un oportuno tratamiento a las elaboraciones plástico-visuales con la aportación de una teoría que hila el surgimiento de una normativa contemporánea de la dominación con los contenidos visuales presentes en entornos específicos. Como cuerpo de conocimiento, la teoría del plast poder supone pensar la realidad desde la experiencia de dominación y generar conocimiento útil para los procesos descriptivos que se realicen sobre las superficies del campo. Contribuye a minimizar los criterios erróneos que pudiesen enunciarse sobre los objetos de investigación en el campo, con una episteme de tipo sintética carente de contradicciones lógicas en su funcionamiento, con una acertada descripción de un mundo de la experiencia posible. Ese conocimiento responde a la realidad de dominación desde donde se produce e intenta describir acertadamente sus procesos en el campo de la comunicación visual.

El entorno social deviene de una estructuración patriarcal, capitalista y occidental, y las relaciones de dominación imperantes responden a las requerimientos de función de tal sistema, las elaboraciones visuales revisten los criterios de legitimidad de los grupos que ejercen poder desigualmente sobre las poblaciones dominadas. Por ende, el plast poder se presenta como una opción interpretativa de las funciones de la comunicación visual al 
Plast poder: El ejercicio de poder estructural focalizado sobre los contenidos

Artículo visuales (Guía de comunicadoras visuales en Costa Rica año 2020)

facilitar una descripción de los hechos acaecidos en el campo en función de las relaciones de poder existentes, lo que induce un empoderamiento de los grupos ubicados al margen del campo, al transformar el sistema de opresión, los privilegios y los accesos a los capitales desprendidos. Al respecto, Acha (1979), en texto de Olivar (2015), señala que "debemos conocer ..., teorizar las realidades que nos urge transformar" (p. 322). La superación de las relaciones desiguales de poder pasa tanto por develar la realidad desde los contenidos visuales, como por la apropiación de los medios de validación y divulgación de tales contenidos. Se vuelve impostergable generar marcos teóricos que faciliten tal apropiación en el contexto de una transformación inclusiva del entorno social.

\section{Referencias:}

Acha, J. (1996). Aproximaciones a la identidad latinoamericana. México D.F.: Escuela Nacional de Artes Plásticas, Universidad Nacional Autónoma de México.

Álvarez, J. (2006). Mujeres centroamericanas y práctica artística: interpretación de la realidad desde el lenguaje del arte, un estudio de casos en Honduras y Costa Rica (tesis de licenciatura). Universidad de Costa Rica, San José.

Bourdieu, P. (1976). El oficio del sociólogo. Madrid: Ed. Siglo XXI.

Bustos, A. (1995). La globalización en los sistemas productivos y financieros: conceptualización, historia y contemporaneidad del proceso con mención del caso de Costa Rica. San José: Editorial de la Universidad de Costa Rica.

Castells, M. (2006). La sociedad red: una visión global. Madrid: Alianza.

Charles, A. (2017). El acceso y participación en la práctica artística de mujeres artistas costarricenses (tesis de licenciatura). Universidad Nacional de Costa Rica, Heredia.

Corrales, J. (1994). Al bienestar por el liberalismo. San José: Editorial Banco Central de Costa Rica / Impresos CQM.

Cubillos, J. (2017). Reflexiones sobre el concepto de inclusión social: una propuesta desde la teoría feminista para el estudio de las políticas públicas. DOl: http//dex.doi.org/10.5209/ POSO. 52735.

Giner, S. (2003). Teoría sociológica moderna. Barcelona: Ariel. 
Hinkelammert, F. (1996). El mapa del emperador: determinismo, caos, sujeto. Recuperado de https://www.pensamientocriticoinfo/...español? ...el20\%mapa20\%del20\%em...

Hinkelammert, F. \& Mora, H. (2001). Coordinación social del trabajo: mercado y reproducción de la vida humana. San José: Departamento Ecuménico de Investigación.

Mandel, C. (2006). Un mapa del cuerpo femenino y su deconstrucción en las artes visuales contemporáneas (tesis de maestría). Universidad de Costa Rica, San José.

Olivar, D. (2015). De la necesidad a la búsqueda: el arte latinoamericano y los aportes de Juan Acha (tesis doctoral). Universidad Carlos III de Madrid, España. Recuperado de https://e-archivo.uc3m.es/handle/10016/23070

Reuber, S. (1995). Crónica de un desajuste social. San José: Editorial de la Universidad de Costa Rica.

Sassen, S. (2003). Contrageografías de la globalización. Género y ciudadanía en los circuitos transfronterizos. Madrid: Traficantes de Sueños.

Sartori, G. (1998). Homo videns: La sociedad teledirigida. Buenos Aires: Taurus.

Schumacher, C. (5 de noviembre de 1999) ¿Es culturas?: La IV Bienal de Escultura de la Cervecería Costa Rica desata críticas. La Nación. Recuperado de http://wvw.nacion. com/viva/1999/noviembre/05/cul1.html

Sosa, R. (2010). Estrategias artísticas feministas como factores de transformación social: un enfoque desde la sociología de género. Cuadernos de Investigación y Comunicación (15), 187-196. Recuperado de https://revistas.ucm.es/index.php/ClYC/article/view/ClYC1010110187A

Vargas, A. (2001). Enfoques evaluativos. Revista de Ciencias Sociales (93), 35-43. Recuperado de https://www.revistacienciassociales.ucr.ac.cr/images/revistas/RCS92_93/03.pdf 
Plast poder: El ejercicio de poder estructural focalizado sobre los contenidos

Artículo visuales (Guía de comunicadoras visuales en Costa Rica año 2020)

\section{Anexo. Guía de comunicadoras visuales:}

Kristina Pérez Baes: la autora Pérez Baes remite el borde discursivo sobre cómo las relaciones de poder se configuran desde los objetos y las relaciones cotidianas, en las cuales el lenguaje recrea los códigos del poder patriarcal imperante con el auspicio institucional de la educación. El tratamiento del borde espacial en su obra tiende a ser inestable y fuera de lo convencional, con zonas móviles y el uso de objetos recuperados.

Mariela Álvarez: en su trabajo, la artista Álvarez Herrera cuestiona los lineamientos de la escultura tradicional, según la disposición de la obra en el espacio y el uso de los materiales; este se dirige hacia la rigidez de la estructura patriarcal y del cómo actúa en las personas. El tratamiento espacial rebasa los límites propios de la escultura convencional.

Lucía Cordero: en un reportaje periodístico recuperado de un antiguo diario, la artista permite que el texto ocupe la posición central dentro de la obra, con lo cual deja el aspecto estético a un lado para maximizar el alcance conceptual propio de la comunicación requerida para entender la propuesta. El trabajo de investigación y documentación de Cordero sustituye al de tipo estético que se ha dejado al borde en el proceso de creación. La extraña muerte de un grupo de ecologistas en la década de 1990 cuestiona el discurso de la supuesta paz social promovida por los grupos de poder dominantes en Costa Rica.

Valeria Ulate: documenta mediante la fotografía con fidelidad el entorno de la Costa Rica rural ubicada al borde de la urbe a finales de la segunda década del siglo XXI, con sus carencias de subsistencia marginal. Valeria Ulate se acerca al contenido de borde al darle un tratamiento estético a elementos de tipo ético vinculados a las relaciones de poder dominante y a las poblaciones en condición de vulnerabilidad que accionan en el campo económico.

Glo Cisneros Zumbado: la obra de Glo Cisneros se inscribe en los bordes de la plástica y la comunicación visual tradicional, pues esta elabora desde el maquillaje corporal facial sus propuestas. En la obra Antes y después, la artista explora el tema de la violencia física hacia las mujeres en el entorno del patriarcado; en la modelo una mitad del rostro recibió maquillaje social de noche, mientras que en la otra mitad se ve el maquillaje, pero luego de una experiencia de violencia doméstica.

Mat Kar: la obra de Mat Kar versa sobre las diferentes formas de expresión del poder patriarcal en el entorno social. La autora remite al tipo de poder que atraviesa el cuerpo de la mujer y le atribuye roles y posiciones, al soportar sobre la humanidad tal condicionamiento 
como borde discursivo del campo de la dominación. En algunas de sus obras, Mat Kar incluye el uso de materiales como latas, puertas o telas para soportar sus propuestas; en el montaje para la obra en la muestra Geofeminista, las tiras rojas salían de la fotografía colgada en la pared y caían hasta el suelo a los pies de quien espectaba.

Cristina Fatjo: la obra fotográfica y de video-arte de Cristina Fatjo utiliza el montaje de objetos fabricados por ella misma y remite a la violencia estructural ejercida sobre poblaciones en condición de vulnerabilidad, ubicadas en los márgenes, a las que el capital tiende a violentar rapazmente. En ocasiones ha realizado montajes en los que la fotografía es colocada en el suelo, lo que amplía el borde espacial y rompe los límites establecidos para este fin.

Man Yu: en su propuesta pictórica (en particular en la colección Traje humano), la pintora china-costarricense hace referencia a cómo la piel que habitamos está socialmente construida y cómo nos desprendemos de esta al encontrarnos en realidades que se dan al borde del campo social, a las que llevan las relaciones de poder propias del sistema patriarcal. El borde espacial en la obra de Man Yu está referido por el cuerpo modelado, mas su propuesta se extiende hasta el diseño de modas para contribuir a sacar la propuesta de la pared, desplazando el margen y la función.

Karla Solano: el trabajo tanto de gigantografías y de video-arte de Karla Solano busca ubicar, en los bordes del cuerpo, el límite de alcance de lo que se percibe visualmente. La obra de Solano refiere a un acercamiento donde el margen de la acción visible es el cuerpo mismo a través del que se ha de leer el contexto que se supone más allá de los márgenes de la acción focalizada y referida a cuerpos de seres ubicados en el margen del interés extractivista patriarcal.

Gabriela Novoa: la artista Novoa aborda el tema de las capacidades autonómicas de las mujeres, los procesos de sororidad y apoyo mutuo entre mujeres que transcurren en los bordes del campo del ejercicio de poder patriarcal. La experiencia, documentada en video, trasciende el uso tradicional del cuerpo dentro de la obra, al fomentar una construcción de tipo feminista que remite a los procesos que se proponen desde la teoría, autonomía y sororidad para la superación de las relaciones patriarcales de ejercicio de poder.

Natalia Aguilar: en su obra, la autora Natalia Aguilar aborda diferentes patologías psicosociales, relacionadas con la forma en que se percibe el cuerpo socialmente construido; lleva a la persona al borde de sus vínculos con lo real y la vulnerabiliza al marginarla. En cuanto al borde espacial, la autora llega a exhibir sus obras, incluso, usando el piso de la 
Plast poder: El ejercicio de poder estructural focalizado sobre los contenidos

Artículo visuales (Guía de comunicadoras visuales en Costa Rica año 2020)

galería como soporte. Genera bordes que superan la espacialidad de la escultórica formal y rigorista de tipo masculinizada, lo que ubica la obra de Aguilar en el borde de tal campo.

Muñecas Chinas: la obra de performance y video-arte de estas realizadoras ubica su atención en el tratamiento ético de las relaciones de poder operantes en el contexto del patriarcado, cuestiona sus discursos y sus formas de manera directa e implementa procedimientos emergentes en la tarea comunicativa. El cuestionamiento de las prácticas de dominación imperante ha llevado a las Muñecas Chinas a exponer su propio cuerpo en acciones que las transgreden para llegar al grado de comunicación efectiva que se proponen lograr. Muñecas Chinas se conforma por Coraima Torres y Ericka Secuie.

Anna Matteucci: el trabajo de Matteucci se ubica en los bordes del dibujo formal, pues la evocación a un estilo menos acabado del color y la línea, a manera infantil, es un acercamiento de ruptura con los medios, estilos y contenidos de tipo académico, en un intento de posicionarse en el borde del campo, con el fin aparente de romper con los modos masculinizados de elaborar el dibujo. El cuestionamiento al adoctrinamiento social a los niños, a través del contenido religioso, los juegos, los personajes de ficción, la democracia, las redes sociales y el capital es recurrente en su producción.

Stephanie Chaves: la artista ubica su obra en los bordes discursivos del campo y desde el feminismo al plantear el reto a la sociedad patriarcal de modificar los modos de interrelación desigual entre hombres y mujeres a manera de superación de las estructuras patriarcales de opresión basadas en el género, la clase social y la raza. Chaves ha venido posicionando sus contenidos visuales abiertamente feministas, con un alto dominio de la teoría y el diseño gráfico, la pintura, el dibujo y, a la vez, con un tipo de happening en vía pública, en el que expone su propio cuerpo y reta a 'acosadores callejeros' con los que se topa. El impacto de su obra en el campo de la comunicación social la ha posicionado como figura pública y su trabajo es representativo de su generación.

Nicole Román: la obra fotográfica de Nicole Román es un acercamiento desde el borde discursivo a las realidades de opresión y desigualdad que vulneran a las mujeres y la población LGBTIQ. En su obra, la autora remite al proceso objetual al que es sometida la mujer en la sociedad patriarcal-capitalista, donde puede estar disponible para consumo y posterior desecho en el entorno del libre mercado. El trabajo de Román en fotografía extiende su campo espacial al incorporar la foto a un objeto mayor, donde la autora logra una exquisita simbiosis entre foto, arte y objeto.

ESCENA. Revista de las artes, 2021, Vol. 81, Núm. 1 (julio-diciembre), pp. 85-112 
Ivania Lasso: es una de las artistas que trabaja con mayor acierto el concepto desde el objeto. En una de sus obras, la autora coloca una bombonera con fichas que, al rasparse, revelan datos estadísticos acerca de las realidades de violencia y desigualdad en la que se desenvuelve la mujer en el entorno patriarcal. Lasso lleva el límite del borde espacial hasta la mano del espectador, quien puede tomar los tiquetes, rasparlos y conservarlos. En sus obras, Lasso utiliza objetos recuperados en los bordes de las realidades sociales, sin aparente significación, mas llenos de contenido conceptual sobre la realidad a la que remiten.

Marcia Hernández: remite con su arte textil a los procesos de construcción de la identidad desde el discurso inclusivo, en igualdad de condiciones de género con ausencia de privilegios y privaciones. Con su trabajo, la autora refiere al desarrollo y la construcción de formas de correlación humana emergentes y disociadas de las pretensiones sistémicas de anulación de la persona desde la privación asignada por género, raza y clase social. Marcia Hernández es una de las artistas mujeres costarricenses que experimenta más cercanamente la desigualdad de género, pues radica y trabaja en Medio Oriente.

Ministra: la fuerte obra visual de Ministra, colectivo de artistas, abarca desde el grafiti urbano, pasando por la pintura, hasta el happening y video, y remite a las condiciones de violencia estructural a las que son expuestas las personas bajo el sistema de privilegios y privaciones propio del patriarcado capitalista. Ministra ha utilizado, al mostrar sus obras, marcos quemados recogidos de incendios, con los cuales, incluso, se ha quemado la pared en la que se colgó la pieza. Ministra es un colectivo de artistas que incluye a la comunicadora Sabrina Ramos y su trabajo genera alto impacto. A la vez, Ministra incursiona en el happening y video-arte con temas como migración y violencia de género.

Ana de Vicente Sanz: la artista cuestiona el rigorismo del sistema patriarcal-estatal respecto del trato que se les da a migrantes y personas refugiadas en el sur de España y otras zonas de Europa. La fotógrafa y performer lleva a los asistentes en su acción a un cuarto en el que, sin percibirlo, entran en un campo performático donde son despojados de sus cosas personales, enumerados, marcados e interrogados, algunos requisados. La artista de origen vasco, de larga data y residencia en Costa Rica, confronta las prácticas de segregación y confinamiento de tipo masculinizado para la solución de los conflictos derivados del sistema de acceso desigual a los capitales presentes en el campo.

Melina Dada: el trabajo de Melina Dada es un acercamiento a la comunicación visual desde los bordes de la práctica, en la cual la obra se reduce a imprimaciones sobre una 
Plast poder: El ejercicio de poder estructural focalizado sobre los contenidos

Artículo visuales (Guía de comunicadoras visuales en Costa Rica año 2020)

camba del útero retirado a una mujer, tras un procedimiento de esterilización. Dada lleva el borde discursivo hasta el punto de retar las prácticas legitimadas por los grupos que detentan el poder, en relación con los procedimientos de control de natalidad que, con un enfoque masculinizado, se vuelven altamente invasivos sobre el cuerpo de la mujer.

Rocío Con: la artista Rocío Con, realiza una investigación en los bordes de la historia china-costarricense, al referirse al inicio de la presencia de la comunidad china en Costa Rica y la registra con documentos recuperados y anotaciones propias. Con trae al centro la experiencia de esta comunidad en sus inicios en este territorio mientras proyecta en el proceso una amplitud de vivencias marginales objetivas y otras subjetivas.

Yorbier Artigas: la obra cerámica de Yorbier Artiagas acerca al relato desde el borde de la realidad social y el margen discursivo de la violencia infantil en una obra que evoca cómo el sistema patriarcal reproduce antivalores como el asesinato. El trabajo cerámico de Artiagas posiciona en los márgenes del interés extractivista del mercado.

Karina Torres: la obra pictórica de Karina Torres, que irrumpe con un sugestivo y fuerte uso del color y con un borde discursivo orientado por la teoría feminista, expresa el tipo de poder dominante en las figuras fálicas centrales. Recurre al uso del texto dentro de la obra como elemento que refuerza lo comunicado visualmente.

Irene Barrantes Jiménez: la obra de Barrantes Jiménez se mueve en los bordes de la plástica convencional al orientar la reflexión sobre los procesos impositivos del patriarcado capitalista en la condición humana de la mujer y sobre su cuerpo de forma violenta y sistemática. Usa técnicas de borde espacial difuso como la performance. Barrantes Jiménez mezcla el arte visual con la militancia política.

Karla Herencia: la obra de Herencia se sitúa en los bordes de la elaboración escultórica al usar materiales de tipo industrial de plástico amorfo. Intenta llevar a una deconstrucción de la persona desde su organicidad interna, lo cual alude a los procesos de significación que inciden en su actuación social. La obra de Herencia apunta a deconstruir la escultura tradicional y sus límites formales.

Pía Chavarría: en la obra de Chavarría se interpreta la autonegación del sujeto ante el entorno que le es adverso por los mecanismos de creación de estructuras patriarcales que, al operar de forma diferenciada, empujan a ciertos grupos a los bordes, al margen de la vinculación formal con la sociedad. Los restos sin rasgos difieren del borde espacial lineal. 
Nancy Rodríguez: la obra textil de Rodríguez reemplaza el típico uso de significación del objeto (en su caso, muñecos de peluche), desde la imagen, al sustituir al oso clásico por un pollo al que se le han cortado alas y pico, remite a cómo los procesos de socialización incorporan los centros referenciales para la interpretación del mundo. El borde espacial es difuso y deconstruye la obra escultórica con materiales textiles.

House of Weysas: el colectivo House of Weysas ofrece una representación de la deconstrucción de los discursos dominantes en una puesta performática que se mueve en el borde muy al margen de los discursos artísticos oficiales. El aspecto espacial es el cuerpo mismo, los territorios de las integrantes del grupo (como Úrsula de los Palotes), a quien se le ha visto transgredir los límites entre el arte y lo profano en plena vía pública.

Ediviette Lobo: la obra de Lobo se circunscribe en las elaboraciones que abordan contenidos tradicionales, como la pintura de imágenes florales, al ser una autora folclórica. Es una herramienta que remite a accionamientos de poder dominantes a partir de la condición humana de quien, desde su cuerpo, ha sido sujeta de accionamientos de poder patriarcal y busca contenidos expresivos en los bordes del discurso.

Celeste Polimeni: el trabajo de Polimeni en video-arte apela al cómo, desde el arte, se deconstruyen las relaciones de poder imperantes y se facilitan canales de expresión que permean a las creadoras visuales desde su propia significación como sujetas en apropiación de su cuerpo, el que usa como lienzo en el transcurrir de la pintura.

Stephanie Williams: el uso del recorrido sonoro de la propia voz de la artista, en su registro impreso y el uso de la fotógrafa autorreferencial, hacen de la obra de Williams un intento por traer al centro modos marginales de crear el producto de comunicación visual, con la apropiación del sonido como recurso estético y documental. En su obra, la artista acerca su propio cuerpo a la elaboración de la obra y reflexiona sobre las distintas posibilidades del recorrido como elemento de reivindicación feminista.

Carolina Rodríguez: la obra de esta artista costarricense radicada en Estados Unidos se ha basado en documentar su recorrido como mujer que transita, se desplaza y documenta. Ese afán de Rodríguez por hacer de la pintura un medio de documentación de su recorrido y, con ella, el de todas las mujeres, la acerca a la construcción desde los bordes del campo de los contenidos. 
Plast poder: El ejercicio de poder estructural focalizado sobre los contenidos

Artículo visuales (Guía de comunicadoras visuales en Costa Rica año 2020)

Lucia Madriz: la obra de Madriz, consecuente con sus orígenes, se ha mantenido, hasta la fecha, en la descripción de las superficies relativas al género, la identidad y el feminismo. Madriz, heredera de contenidos y prácticas de Pérez Ratton -con quien trabajó de cerca-, aborda los márgenes de la realidad patriarcal, al reconstruirlos para llevarlos al centro en formas estéticas y conceptuales afines a los contenidos inclusivos.

Kate Fernández: su propuesta se sitúa en los bordes del dibujo y la pintura formal, al transgredir los límites del borde espacial con extensiones que rebasan sus linderos con el uso de hilo, cable y otros materiales que expanden su obra. El tratamiento del dibujo es magistral y, desde la anatomía, crea atmósferas surreales que recuerdan el trabajo de Khalo o Salazar Rahxo, en una búsqueda de contenidos subconscientes que remiten a la corporeidad como territorio de reivindicación femenina.

Florencia Urbina: en el trabajo pictórico de Urbina, miembro del colectivo Bocaracácon, su amplia paleta de color remite a los territorios no humanos como espacios depredominio natural que prevalecen ante la arremetida que, durante las décadas de 1990 y 2000, tuvo la política neoliberal en América Central. Urbina circunscribe su obra dentro de la corriente del arte pop, estilo representativo en Costa Rica.

Diedrid Hyde: ubica su obra en los límites del borde discursivo dominante, al cuestionar los lineamientos del crecimiento industrial y económico en detrimento del bienestar humano y ambiental. Se considera la pintura de Hyde como parte de la teoría del decrecimiento desde el arte visual, aunada al tratamiento plástico con el uso de amplias zonas oscuras. Su participación en la muestra Antropoceno, curada por Irene Antillon de la 3ra Edición de Lanobienal, es referencial.

Aime Joaristi: la obra realizada por esta autora para el espacio llamado Mascarillas solidarias, con motivo de la prevención de la transmisión de la COVID-19, es un alarde de transgresión al borde espacial, pues usa una mascarilla bocal como soporte de la obra y la dota de una serie de espinas naturales que se expanden en múltiples direcciones. El borde discursivo dominante, que promueve una inducción a formas de convivencias socialmente armónicas, es cuestionado al remitir esta obra a modos de convivencia en un entorno social deconstruido con el advenimiento de la pandemia sanitaria global.

Alessandra Sequeira: el trabajo de Sequeira usa elementos biodegradables, como el cordón de cabuya. En su participación en la muestra Land Art, de la 3ra Edición de Lanobienal, deconstruyó los bordes espaciales del arte visual desde la formalidad dominante; usó el 
suelo como soporte de la obra. Desde lo discursivo, cuestiona el predominio de la retórica patriarcal, al focalizar su interés en promover puntos de vista diferenciados y múltiples, lo que remite a la intersección social.

ImPaYasas: el trabajo de este colectivo de performance, en el que participa la artista Ixmu Kane, es una crítica continua a los valores dominantes del sistema patriarcal que tiende a someter a los cuerpos a una disciplina de represión y que castiga el uso del cuerpo para accionar espacios de liberación. En el caso de ImPaYasas, se recuerda la marcha que realizaron desnudas las mujeres entre la Universidad de Costa Rica y el Centro Comercial Muñoz y Nanne en el año 2017, ampliamente documentado en medios de comunicación.

Priscilla Jiménez: la obra de Priscilla Jiménez para la 3er edición de Lanobienal (2020), sobre arte de La Tierra, propone un borde discursivo sobre los procesos de degradación ambiental, propio del sistema patriarcal y capitalista, en el cual los ecosistemas no humanos tienen una condición marginal. El borde espacial transgrede los lineamientosde la escultura formal, pues ubica la obra fuera del museo y la despoja de valor comercialal usar materiales naturales y biodegradables que se modifican con el tiempo.

Vanessa Navarro: la relación humana con otras especies, en la lógica patriarcal, está tamizada por la subordinación, la violencia y la utilización. La obra de Vanesa Navarro alude en lo discursivo al comportamiento social que focaliza el consumo sobre el bienestar animal. Es impactante la propuesta explícita de la violencia patriarcal a la que son sometidas tanto especies animales como mujeres en la sociedad del libre mercado.

Nadia Mendoza: la obra pictórica de Mendoza, de estilo abstracta, alude con sus color diverso y uso de líneas desiguales, a un borde discursivo de relativismo sobre la identidad humana y de la ilusión de la libre elección en la sociedad capitalista. Mendoza fue miembro del grupo La Nueva Escuela a inicios del siglo XXI.

Carolina Guillermet: el predominio de formas geométricas en la propuesta de Guillermet, incorporadas en tapetes para piso, expande el borde espacial de una obra convencional, al usar el suelo como soporte. En lo discursivo propone la ruptura entre lo formal y lo aparente, como signo distintivo de la lógica occidental post moderna.

Chenna Lobo: realiza un happening en que saca a seis reclusas de la cárcel para mujeres y las lleva a una nuestra de arte, con lo cual rompe el mandato punitivo del patriarcado y deconstruye la función y bordes de la obra de arte visual. 
Plast poder: El ejercicio de poder estructural focalizado sobre los contenidos

Artículo visuales (Guía de comunicadoras visuales en Costa Rica año 2020)

Flavia Mora: el trabajo visual de Mora se ubica al borde del campo de la comunicación visual al combinar el arte con la militancia política, ella realiza happenings en vía pública a modo de bloqueos de calles. A la vez, la artista incursiona en el diseño de joyería usando técnicas artesanales y detallada elaboración.

Ximena Cedeño: la propuesta de Cedeño parte de la palabra para realizar performance, a modo de declamación poética, acerca de milicias de mujeres, sororidad e igualdad de género. El uso enfático de la palabra deconstruye el borde espacial y discurso.

Mimian Hsu: la obra de Hsu trae al centro las relaciones culturales entre la comunidad china y la costarricense. Rompe el borde espacial de la obra al realizar performance con el uso de ropajes folclóricos con motivos chinos elaborados como arte textil.

Karina Milner Barquero: el proyecto "Fiero Corazón" de la comunicadora visual Karina Milner se posiciona en el borde del discurso dominante con una propuesta que apunta a deconstruir el ideal hetero normativo patriarcal. Faculta de dibujo y palabra un modelo de educación sexual para adultos que trae al centro la opción de configurar identidades de género inclusivas.

Duvi Carranza: la obra de la artista Carranza se basa en la recolección de tierras de variados colores, recogida en diversos parajes de Costa Rica. Su obra "Tierriticas", presentada en la Lanobienal 3ra Edición, consiste en un cilindro transparente de medio metro de alto, relleno de tierra en sesenta y seis colores diferentes, reivindicando la diversidad desde el objeto.

Yatzil Marin Alvarez: la niña Yatzil Marin genera desde el "Taller Carebarro", de la Fundación Keme, un acercamiento discursivo a los derechos culturales de las personas menores de edad, en su participación en Lanobienal 3ra Edición, con una interesante escultura en barro.

ESCENA. Revista de las artes, 2021, Vol. 81, Núm. 1 (julio-diciembre), pp. 85-112 